

\title{
Trabalhadora feliz, mãe feliz? Condições de trabalho que influenciam na vida familiar
}

\author{
Happy worker, happy mother? Working conditions that affect family life
}

Sabrina Mazo D'Affonseca ${ }^{[a]}$, Fabiana Cia ${ }^{[b]}$, Elizabeth Joan Barham ${ }^{[c]}$

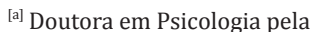
Universidade Federal de São Carlos, São Carlos, SP - Brasil, e-mail: samazo@hotmail.com

${ }^{[b]}$ Doutorado em Educação Especial, professora adjunta do Departamento de Psicologia e do Programa de Pós-Graduação em Educação Especial da Universidade Federal de São Carlos, São Carlos, SP - Brasil, e-mail: fabianacia@hotmail.com

${ }^{[c]}$ Doutora em Psicologia Social e de Desenvolvimento Aplicada, professora da Universidade Federal de São Carlos, São Carlos, SP - Brasil, e-mail: sa@power.ufscar.br
}

Recebido: 27/02/2012 Received: 02/27/2012

Aprovado: 05/06/2012 Approved: 06/05/2012

\section{Resumo}

A presente pesquisa objetivou verificar quais aspectos do trabalho poderiam afetar positiva ou negativamente o relacionamento de mães trabalhadoras com seus filhos. Participaram da pesquisa 23 mães que trabalhavam fora, com pelo menos um filho cursando o ensino fundamental. A coleta de dados envolveu o preenchimento do "Questionário sobre Interação Familiar na Visão Materna”, elaborado pelas autoras, o qual possuía questões referentes: (a) ao ambiente de trabalho; (b) ao relacionamento com os filhos; (c) ao apoio dos familiares para a realização de atividades domésticas. Os resultados demonstraram que a satisfação com o trabalho possuía uma correlação positiva com a participação da mãe nas atividades culturais, escolares e de lazer dos filhos e com o apoio recebido de seu cônjuge para a realização de tarefas domésticas. Dessa forma, pode-se dizer que a qualidade do ambiente de trabalho atua como um mediador para o estabelecimento de relações familiares positivas e para o desenvolvimento socioemocional e escolar dos filhos.

Palavras-chave: Maternidade. Trabalho. Relações familiares.

\section{Abstract}

This study aimed to verify which aspects of work could positively or negatively affect the relationship of working mothers with their children. Twenty-three working mothers with at least one child in elementary school participated in the survey. Data collection involved the completion of the "Questionnaire on Family Interaction in Maternal View", which was elaborated by the authors and contained questions referring to: (a) the working environment; (b) the relationship with their children; (c) the support of family members to carry out household chores. The results demonstrated that job satisfaction had a positive correlation with the mothers' participation in cultural, educational and recreational activities of their children and with the support received from their spouse to carry out household chores. Thus, one can say that the quality of the work environment acts as a mediator for the establishment of positive family relationships and socioemotional and educational development of their children.

Keywords: Maternity. Work. Family relations.

Psicol. Argum. 2014 jan./mar., 32(76), 129-138 


\section{Introducão}

A participação da mulher no mercado de trabalho despertou o interesse de muitos pesquisadores ao longo dos anos e foi uma das mudanças sociais responsáveis pela entrada dos estudos sobre a mulher na academia brasileira (Bruschini, 2006; 2007).

Com a atual evolução dos trabalhos nessa temática, estudiosos buscam compreender como ocorre a articulação entre a participação da mulher no mercado de trabalho e seu papel na família e quais os impactos positivos e negativos de diferentes arranjos para todos os envolvidos, especialmente os familiares dependentes. Assim, no presente trabalho discutiremos algumas variáveis sociais e econômicas que contribuíram para a permanência da mulher no mercado de trabalho após o nascimento dos filhos, os impactos que isso teve em sua saúde física e mental e suas implicações para o equilíbrio entre demandas profissionais e da família, focando mães de crianças no ensino fundamental.

Por fim, apresentaremos os dados da pesquisa realizada, a qual buscou verificar como os aspectos do trabalho podem afetar positiva ou negativamente o relacionamento de mães trabalhadoras com seus filhos.

\section{Mulher e trabalho}

De acordo com Cortazzo e Moise (2000), o trabalho (remunerado ou não) se constitui como uma atividade social que permite ao indivíduo incorporar-se na comunidade como um elemento produtivo, e as trocas estabelecidas nesse local fazem que o mesmo tenha reconhecimento e valorização social. Assim, o trabalho completa e complementa o processo de socialização do indivíduo e pode ser uma fonte de valorização e prazer que pode levar tanto o sentimento de utilidade e transcendência como frustrações crônicas quando excessivamente repetitivo, sem contribuir para um senso de avanço ou desenvolvimento.

Considerando a participação da mulher no mercado de trabalho, nota-se que elas sempre trabalharam, seja realizando trabalhos remunerados ou não. A grande maioria das mulheres tem assumido responsabilidades diretas para cuidar das pessoas e pertences ligados à sua vida familiar - ter filhos, cuidar dos filhos e demais familiares, cozinhar, limpar e administrar o trabalho da casa (McGoldrick, 1995). Contudo, alguns dos benefícios de ter uma renda própria (financeiros, de contato social com pares e de reconhecimento social) dificilmente podem ser obtidos exclusivamente por meio do trabalho direcionado à sua própria família, o que fez que as mulheres passassem a buscar estes benefícios no mercado de trabalho à medida que começaram a ter maior controle sobre as demandas familiares ligadas ao número de filhos. A possibilidade de ingresso no mercado de trabalho formal e remunerado foi considerada uma conquista na história da mulher, sendo alavancada na década de 1970, contribuindo para uma maior autonomia em todas as dimensões de sua vida, culminando em uma melhoria na saúde mental das mulheres.

Assim, nota-se que atualmente a maioria das mulheres brasileiras entre 15 e 60 anos estão presentes no mercado de trabalho (Bruschini, 2006), sendo este um fenômeno mundial que tem ocorrido tanto em países desenvolvidos como em países emergentes ou em desenvolvimento (Probst \& Ramos, 2003). No Brasil, a partir da década de 1950, houve um aumento progressivo no número de mulheres exercendo atividades remuneradas em função da intensificação do processo de industrialização e urbanização. A partir da década de 1980, os empregos dependiam cada vez menos do esforço físico e cada vez mais de habilidades sociais e intelectuais, facilitando a inclusão das mulheres no mercado de trabalho, que agora passaram a exercer profissões antes praticadas somente por homens (Maluf \& Mott, 1998). Estudos têm demonstrado que o trabalho remunerado ocupa uma parte cada vez mais importante na vida das mulheres, e estas vêm se profissionalizando e atuando em áreas tradicionais e não tradicionais (Bruschini \& Lombardi, 1999), sendo que hoje não existe uma divisão tão forte entre os empregos ocupados por homens e mulheres.

A despeito do foco social na inclusão de mulheres no mercado de trabalho, atualmente, segundo Bertolini (2002), a mulher busca tanto a realização pessoal quanto profissional, desejando independência econômica enquanto preserva seu papel de mãe. A construção de uma identidade profissional é fonte de status, poder e autoestima, contribuindo para uma melhor saúde mental da mulher, o que pode favorecer relacionamentos interpessoais mais positivos na esfera familiar, inclusive com os filhos 
(Bertolini, 2002; Gravena, 2006; D’Affonseca, 2005). No entanto, a intensidade do envolvimento da mulher com a carreira e a importância atribuída a esta para sua identidade pessoal são fatores que podem provocar problemas de saúde física e mental quando a pessoa sente dificuldade para lidar com as condições e demandas de trabalho, bem como quando as atividades laborais entram em concorrência com as demandas para cuidar de filhos, principalmente durante a infância e adolescência destes (Diniz, 1999).

\section{Dificuldades encontradas por mulheres no equilíbrio entre trabalho e família}

Apesar das alterações sociais ocorridas nas últimas décadas, a mulher ainda é mais sobrecarregada pela soma de tarefas profissionais e domésticas do que o homem. Em uma revisão de pesquisas apresentadas por Bruschini (2006), podemos observar que o maior envolvimento das mulheres no trabalho doméstico acaba reduzindo todos os seus outros espaços temporais, sobretudo os de lazer e descanso, e isto é observado tanto em países industrializados como em países não industrializados. Bruschini (2006) alerta que o tempo de preparo para inserção no mercado de trabalho e o tempo de dedicação à profissão (o "tempo econômico") estão aumentando, e esta demanda é igual para homens e mulheres do mesmo nível profissional. Isto prejudica mais a mulher do que o homem, uma vez que o tempo dedicado por elas à manutenção de sua rede social e aos cuidados com sua família nuclear ("tempo de reprodução social") não está diminuindo e é significativamente maior do que o dos homens. Assim, a mulher tem seu tempo livre reduzido porque ela adiciona o tempo econômico, que está aumentando, ao da reprodução social, que está se mantendo.

Em função disso, é compreensível que, na visão das mulheres, a atividade oposta ao trabalho profissional não é o lazer, mas o trabalho doméstico e familiar (Antunes, 2003). Os problemas aparecem quando as responsabilidades em cada esfera (trabalho e família) se sobrepõem - por exemplo, um filho doente necessitando de cuidados em um dia de trabalho - ou quando o volume total de tarefas se torna excessivo. Quando ocorrem conflitos entre as demandas profissionais e familiares, é preciso optar entre estas duas responsabilidades altamente importantes, o que leva a custos na vida profissional ou familiar, ou em ambas (Gottlieb, Kelloway \& Barham, 1998). Além disso, a alta demanda constante de tempo para conciliar obrigações familiares e profissionais é um fator de estresse crônico (Bertolini, 2002) que pode provocar o aparecimento de vários sintomas, incluindo doenças físicas, ansiedade, depressão, angústia, dificuldade na resolução de problemas, estresse e baixa produtividade (Cooper \& Lewis, 2000). Mesmo quando as mulheres se recusam a ter de assumir total responsabilidade por manter os relacionamentos familiares e os cuidados da casa, elas frequentemente se sentem culpadas por não realizar aquilo que os outros entendem como sua obrigação. Quando ninguém preenche essa lacuna, elas sentem que a qualidade de vida de seus familiares é inferior ao padrão obtido por outras famílias e acreditam que a culpa é delas (McGoldrick, 1995).

Apesar das dificuldades enfrentadas pelas mulheres com papéis múltiplos, o trabalho remunerado é benéfico e importante para a maioria delas e para seus familiares. Em geral, o trabalho remunerado representa independência econômica na vida adulta e traz reconhecimento social e maior satisfação pessoal (D’Affonseca, 2005). A ampliação de seus conhecimentos, de sua gama de atividades e de seus contatos sociais conduz à formação de uma identidade profissional e proporciona sentimentos de autonomia e utilidade. Assim, o senso de competência aumenta e melhora a autoestima, trazendo benefícios para o desempenho nos papéis familiares. Atualmente, mulheres que trabalham fora tendem a se sentir mais capazes como mães, dispor de melhor saúde física e mental e ter relacionamentos mais satisfatórios do que mulheres donas de casa que gostariam de exercer atividades remuneradas e que, por alguma razão, não puderam exercê-las (desemprego, pouca escolaridade, número de filhos etc.) (D’Affonseca, 2005; Bertolini, 2002; Diniz, 1999; McGoldrick, 1995).

\section{Relacões entre o trabalho da mulher e a dinâmica familiar}

Ao contrário da afirmação, comum em nosso cotidiano, de que quando a mulher trabalha fora, não consegue cuidar adequadamente de seus filhos, algumas pesquisas realizadas com mulheres

Psicol. Argum. 2014 jan./mar., 32(76), 129-138 
empregadas sugerem que estas podem trabalhar fora e satisfazer as necessidades emocionais, físicas e intelectuais de seus filhos em certos contextos, porém isso exige um intenso compromisso dos pais na manutenção de uma relação aberta e amorosa com os filhos e na instalação de um clima doméstico em que as necessidades de todos os membros da família sejam respeitadas (Grollman \& Sweder, 1991).

Embora todas as mães desejem ser justas e tratar os filhos com respeito e paciência, orientando-os e dando o apoio necessário, nem sempre elas conseguem cumprir tais propósitos (Gottman \& DeClaire, 2001). Para melhor entender como a situação das mães pode afetar seu envolvimento com seus filhos, Bertolini (2002) realizou uma pesquisa comparando mães donas de casa com mães que trabalhavam fora no que diz respeito à satisfação com o trabalho e à percepção das mães sobre a relação afetiva com seus filhos. Os dados obtidos demonstram que tanto as donas de casa como as que trabalhavam fora viam vantagens e desvantagens com relação à sua opção de vida, sendo que não existe um ideal.

No caso de ambas as opções, a família precisa encontrar um equilíbrio entre as necessidades financeiras da família e as da qualidade dos cuidados oferecidos aos filhos. Sem um cuidado de qualidade, as crianças apresentam baixo rendimento escolar, brigas com colegas e maior probabilidade de evasão escolar e de apresentar problemas de saúde (Gottman \& DeClaire, 2001). Assim, torna-se importante verificar se algum aspecto do ambiente de trabalho externo da mulher tende a reduzir seu envolvimento em determinadas atividades que são consideradas importantes para a qualidade de seu relacionamento com os filhos.

\section{Objetivo}

Relacionar as condições de trabalho com a frequência de relacionamento entre mães e filhos.

\section{Método}

Participantes

Participaram da pesquisa 23 mães que trabalhavam fora (com idade média de 36,8 anos) com pelo menos um filho cursando o ensino fundamental. A renda familiar das participantes variou de 1 salário mínimo (doravante SM) a $10 \mathrm{SM}$, sendo que a maioria $(59,1 \%)$ tinha uma renda de 2 à 4 SM. A parcela maior das participantes $(33,3 \%)$ possuía segundo grau completo, o que é típico de amostras de pessoas que trabalham fora, porque cada vez mais empregos exigem segundo grau completo. Em relação à função exercida pelas mulheres, a grande maioria (75\%) possuía funções que não exigiam muita qualificação, concentrando-se em serviços (empregada doméstica, faxineira, servente e cabeleireira) ou em empregos no setor da indústria que exigiam segundo grau completo (auxiliar de produção e operadora de máquinas). Além disso, 12,5\% exerciam atividades administrativas, $8,3 \%$ atuavam na área da saúde e 4,2\% na educação, as quais requerem uma formação técnica ou de nível superior.

Critério para participar da pesquisa

Foi utilizado como critério que a participante estivesse exercendo alguma atividade remunerada fora do lar há mais de um ano.

Local

A pesquisa foi realizada nas dependências de uma instituição privada de interesse público, sem custos para as famílias.

\section{Instrumentos}

Foi aplicado o "Questionário sobre a percepção materna a respeito do relacionamento familiar e de seu bem-estar" (D'Affonseca, 2004), o qual possuía questões referentes: (a) ao ambiente de trabalho; (b) ao relacionamento com os filhos; (c) ao apoio dos familiares para a realização de atividades domésticas.

\section{Procedimento}

Após a autorização da direção da instituição, a pesquisadora distribuiu 130 questionários com instruções precisas a respeito do preenchimento do instrumento para as mães dos alunos do sexto e sétimo ano dessa instituição, após uma reunião de pais e por meio dos alunos. Desse total, 60 foram devolvidos, sendo que 23 preencheram os critérios 
da pesquisa. Cabe destacar que a pesquisadora se disponibilizou para esclarecer dúvidas a respeito do preenchimento do instrumento e algumas mães utilizaram esse recurso.

\section{Procedimento de análise dos dados}

Os resultados foram analisados estatisticamente usando medidas de tendência central e dispersão. Para verificar a relação entre os fatores de trabalho e as demais variáveis, foi utilizado o teste de correlação de Pearson.

\section{Resultados e discussão}

Uma questão fundamental quando se fala em trabalho é importância que o mesmo tem para a identidade da pessoa. No caso específico de mães, essa questão ainda é mais capciosa. Em uma pesquisa realizada em São Paulo com mães trabalhadoras e donas de casa apontou que os filhos de ambos os grupos apresentavam maior segurança e melhor relacionamento com as mães quando estas demonstravam satisfação com a posição assumida (Pereira, 1978 citado por Bertolini, 2002). Os dados obtidos demonstraram que as maiores fontes de satisfação das participantes envolveram características da função exercida por elas e seus relacionamentos interpessoais estabelecidos no ambiente do trabalho. Já em relação às fontes de insatisfação, encontraram-se fatores relacionados ao desenvolvimento profissional e financeiro. Esse resultado pode ser compreendido com base nas funções exercidas por essas profissionais, visto que, na maioria das vezes, elas estavam sendo mal remuneradas em relação aos homens e/ou inseridas em cargos que não possibilitam progressões na carreira, como continua sendo o caso de muitas brasileiras.

\section{Condicões de trabalho}

Embora muitas vezes as mulheres possam se sentir razoavelmente satisfeitas com o trabalho, o mesmo pode apresentar algumas dificuldades específicas, como sobrecarga de trabalho, dificuldades no desempenho profissional relacionadas às demandas familiares e falta de apoio interpessoal no ambiente de trabalho. No que se refere à sobrecarga de trabalho, os dados obtidos demonstraram que, aparentemente, as mulheres não possuíam tempo ocioso algum durante o horário de trabalho, mas a maioria também não precisava trabalhar horas extras ou levar tarefas para casa.

Em relação às dificuldades percebidas pela respondentes no que se refere a seu desempenho no trabalho remunerado, a mais frequentemente apontada envolvia conflitos com superiores. As participantes afirmaram que diversos itens não estavam presentes em seu cotidiano: "tive conflitos com meus colegas de trabalho"; "tive de reduzir o número de horas de trabalho por semana"; "cheguei atrasada"; "tive de interromper meu trabalho para resolver outra coisa"; "precisei de um tempo maior de almoço". No entanto, neste caso, a ausência dos casos citados não foi tão favorável, visto que os setores de trabalho das participantes se caracterizavam como setores mais ortodoxos e com pouca possibilidade de arranjos para atender às necessidades pessoais e/ou familiares, o que tornava seu horário menos flexível e a disponibilidade para demandas familiares mais restrita durante o período de trabalho. Além destas demandas no local de trabalho, muitas vezes as participantes dependiam de transporte público, o que prejudicava ainda mais sua disposição para cuidar das questões familiares.

Além da questão da sobrecarga e desempenho profissional, examinaram-se algumas características do ambiente interpessoal de trabalho, e nesse aspecto se encontra a qualidade dos relacionamentos estabelecidos entre os colegas de trabalho e os superiores. De forma geral, as respondentes indicaram que o ambiente interpessoal de trabalho era adequado, sendo que estas recebiam um pouco mais de apoio de seus colegas do que de seus superiores.

Para entender a qualidade da relação entre mãe e filho, investigou-se o quanto trabalhar fora trazia benefícios e dificuldades para o envolvimento familiar dessas mulheres. Com base nos resultados sobre questões ligadas ao trabalho, percebe-se que a maior parte das mulheres nesta amostra estava engajada e satisfeita com suas funções, apesar de lidar com condições de trabalho percebidas como medianamente adequadas. Assim, para parte dessas mulheres, seu emprego pode representar uma fonte de estresse em sua vida familiar.

Interação familiar com os filhos segundo as mães

A literatura da área demonstra correlações importantes entre o envolvimento materno na educação do filho e o desenvolvimento global satisfatório

Psicol. Argum. 2014 jan./mar., 32(76), 129-138 
da criança (Hartmann et al., 2001). Assim, buscou-se avaliar a frequência da comunicação verbal e não verbal com os filhos, sendo que os dados coletados demonstraram que as mães mantinham comportamentos comunicativos importantes para um bom relacionamento familiar, como "dar carinho", "manter diálogo", "expressar sentimentos positivos", "oferecer ajuda", "elogiar", "impor limites" e "cumprir promessas". 0 único comportamento comunicativo que apresentou baixa frequência foi a "expressão de sentimentos negativos". Embora esse tipo de comunicação seja importante para o desenvolvimento emocional e social da criança ou adolescente, ele deve ocorrer com baixa frequência para evitar que ocorram relacionamentos familiares excessivamente autoritários (Gottman \& DeClaire, 2001; Maldonado, 1985; Sayão, 2003). Além da frequência de comunicação com os filhos, buscou-se também verificar a frequência que mães participavam dos cuidados com o filho. Esses dados estão apresentados na Tabela 1.

Em geral, as mães disseram que estavam bastante envolvidas nos cuidados com os filhos. Segundo as respondentes, elas participavam mais frequentemente das atividades relativas à educação social do filho ("punir por comportamento inadequado", "controlar o círculo de amizades", "ir a encontros religiosos" e "ter contato com outros parentes"). Os itens citados com menor frequência pelas mães foram "atender a solicitações para comprar coisas desnecessárias" e "dar mesada", o que pode refletir tanto intenções de educar o filho quanto restrições financeiras presentes nessa amostra.

Os dados apresentados na Tabela 2 demonstram que as mães consideraram que os filhos eram carinhosos, dividiam fatos ocorridos com eles no dia a dia, solicitavam ajuda e as elogiavam, em média, duas ou três vezes na semana. Na maioria dos casos, o relacionamento entre mãe e filhos era descrito como saudável e com poucos conflitos, uma vez que as mães relataram que os filhos desafiavam suas regras apenas uma vez por semana, em média.

De modo geral, as mães relataram haver uma boa comunicação, tanto por parte delas quanto dos filhos, e uma presença regular nos cuidados e na educação dos filhos. Destaca-se, também, que as mães afirmaram que os filhos tinham um bom comportamento e avaliaram positivamente a participação dos pais, os quais, segundo elas, são muito ativos nos cuidados com os filhos. Cabe ressaltar também que as mães disseram passar, em média, 2,21 horas por dia realizando alguma atividade com os filhos, $o$

Tabela 1 - Grau de participação da mãe em alguns aspectos da educação e dos cuidados com os filhos

\begin{tabular}{lcc}
\hline Comportamento da mãe em relação aos filhos & Pontuação & Desvio padrão \\
\hline Punir por comportamento inadequado & 4,79 & 0,52 \\
Controlar o círculo de amizades & 4,63 & 0,88 \\
Ir a encontros religiosos & 4,56 & 1,02 \\
Participar dos hábitos de higiene & 4,48 & 1,12 \\
Ter contato com outros parentes & 4,45 & 1,10 \\
Acompanhar a educação escolar (auxiliar nas tarefas, exigir empenho em relação aos & 4,41 & 1,02 \\
estudos etc.) & 4,29 & 1,07 \\
Regular o horário de deitar & 4,27 & 1,17 \\
Ler livros e revistas para crianças & 4,22 & 1,25 \\
Passear & 4,12 & 1,17 \\
Comprar roupas e brinquedos & 4,10 & 1,25 \\
Controlar o horário de lazer & 3,97 & 1,40 \\
Fazer atividades físicas & 3,80 & 1,43 \\
Controlar o consumo de alimentos com baixo valor nutricional (frituras e guloseimas) & 1,80 \\
Atender a solicitações para comprar coisas desnecessárias & 2,85 & 1,81 \\
Dar mesada & 2,52 & \\
\hline
\end{tabular}

Nota: A pontuação varia entre 1 (nenhuma participação) e 5 (muita participação).

Fonte: As autoras. 
Tabela 2 - Frequência de interação dos filhos com a mãe, segundo as mães

\begin{tabular}{lcc}
\hline Comportamento dos filhos em relação à mãe & Pontuação & Desvio padrão \\
\hline Dar carinho (abraços, beijos) & 4,71 & 0,75 \\
Procurar para conversar & 4,70 & 0,82 \\
Contar as coisas boas ou ruins em relação à escola & 4,68 & 0,77 \\
Solicitar que faça algo por eles & 4,67 & 0,57 \\
Contar as coisas boas ou ruins em relação aos amigos & 4,66 & 0,85 \\
Fazer perguntas referentes a seu dia a dia & 4,53 & 0,89 \\
Fazer elogios & 4,24 & 1,13 \\
Pedir ajuda em alguma atividade (acadêmica ou não) & 4,20 & 1,13 \\
Expressar desejos e preferências, dando razão para suas ações e posições & 3,90 & 1,22 \\
Desafiar suas regras (desobediência) & 3,01 & 1,45 \\
\hline
\end{tabular}

Nota: A pontuação varia entre 1 (nunca) e 5 (uma vez por dia).

Fonte: As autoras.

que se revela um dos principais fatores para o alto índice de participação mencionado.

Participação das mães nas atividades acadêmicas e de lazer dos filhos

Mesmo que as mães possuam relacionamentos saudáveis com os filhos no ambiente familiar, pesquisas demonstram que existem benefícios adicionais quando elas participam ativamente nas conquistas acadêmicas dos filhos, demonstrando interesse e auxiliando-os (Grollman \& Sweder, 1991). Além disso, fornecer estímulos culturais e de lazer para os filhos também contribui para seu desenvolvimento. Assim, buscou-se avaliar a frequência da participação da mãe nas atividades escolares, culturais e de lazer dos filhos (Tabela 3).

Os dados da Tabela 3 demonstram que as mães estimulam os filhos a cumprir tarefas acadêmicas, organizar suas coisas, participar de refeições familiares e cuidar de sua higiene. Entre as atividades de menor participação por parte das mães, encontram-se "ler/contar histórias" e "assistir a eventos culturais", as quais ocorriam, de acordo com as mães, em média, uma vez por mês. Tratando-se deste quesito, é preciso evidenciar a renda mensal das participantes, visto que assistir a eventos culturais envolve um custo muitas vezes pouco acessível para essa população. Outro ponto a ser destacado é a idade dos filhos (de 10 a 14 anos), a qual não favorece algumas dessas atividades, como ler/contar histórias, pois se espera que os mesmos já leiam sozinhos e que a interação com a mãe, nessa idade, tenha um outro perfil.
Relação entre as condições de trabalho das mães que trabalhavam fora e seu envolvimento com os filhos

A literatura aponta que o desempenho familiar de mães que trabalham fora é afetado pelas condições de trabalho às quais são expostas e pela forma como elas experimentam o seu envolvimento no trabalho (Cooper \& Lewis, 2000), isto é, mães mais satisfeitas no trabalho tendem a ter um desempenho familiar melhor. Dessa forma, torna-se importante investigar a influência das condições de trabalho sobre o envolvimento das mães que trabalhavam fora nessa amostra.

Na Tabela 4, pode-se identificar os aspectos do trabalho que estavam afetando a interação das mães com seus filhos. Observou-se uma correlação positiva e significativa entre a satisfação da mãe com o trabalho e: a) sua participação nas atividades escolares, culturais e de lazer dos filhos, confirmando a importância desse fator para o envolvimento da mãe no cotidiano dos filhos; b) a comunicação entre mãe e filho, o que indica que as mães satisfeitas com seu desempenho profissional estavam mais abertas para comunicações mais frequentes com seus filhos.

Além disso, verificamos que o ambiente interpessoal de trabalho possuía uma correlação significativa e negativa com a comunicação com o filho, demonstrando que a interação familiar depende de fatores mais abrangentes que o ambiente do lar. Parece que parte das necessidades de comunicação das mães acaba sendo atendida no ambiente de trabalho, assim, elas não dependem dos filhos para preencher uma falta de conversação. Outra

Psicol. Argum. 2014 jan./mar., 32(76), 129-138 
Tabela 3 - Frequência da participação da mãe nas atividades da vida diária de cuidados escolares, culturais e de lazer dos filhos

\begin{tabular}{|c|c|c|}
\hline Tipo de participação & Pontuação & Desvio Padrão \\
\hline \multicolumn{3}{|l|}{ Atividades escolares } \\
\hline Incentivar a assumir responsabilidade por tarefas escolares & 5,92 & 0,32 \\
\hline Valorizar as conquistas acadêmicas & 5,70 & 0,81 \\
\hline Acompanhar o progresso escolar & 5,49 & 0,86 \\
\hline Auxiliar nas lições de casa & 5,42 & 1,03 \\
\hline Incentivar a leitura (de livros, revistas, jornais etc.) & 5,30 & 1,00 \\
\hline Ler/contar histórias & 3,87 & 1,76 \\
\hline \multicolumn{3}{|l|}{ Atividades cotidianas } \\
\hline Pedir para organizarem objetos pessoais (roupas, brinquedos etc.) & 5,89 & 0,36 \\
\hline Acompanhar nas refeições & 5,85 & 0,69 \\
\hline Auxiliar nas atividades de higiene (escovar os dentes, tomar banho, etc.) & 5,82 & 0,73 \\
\hline $\begin{array}{l}\text { Incentivar a realizar atividades domésticas (cuidar das próprias coisas, da casa } \\
\text { etc.) }\end{array}$ & 5,39 & 1,34 \\
\hline Acompanhar na hora de se vestir & 5,24 & 1,39 \\
\hline \multicolumn{3}{|l|}{ Atividades de lazer e recreativas } \\
\hline Incentivar a brincar com jogos educativos & 5,45 & 0,95 \\
\hline Valorizar as conquistas esportivas & 5,35 & 1,16 \\
\hline Brincar & 5,20 & 0,96 \\
\hline Assistir à filmes de escolha deles & 4,27 & 1,81 \\
\hline Passear (no shopping, zoológico, casa de familiares etc.) & 4,12 & 1,38 \\
\hline Assistir a eventos culturais (teatro, cinema, shows musicais etc.) & 2,69 & 1,54 \\
\hline \multicolumn{3}{|l|}{ Contatos sociais } \\
\hline Incentivar a ter contato com outros adultos (tios, amigos da família etc.) & 5,08 & 1,21 \\
\hline $\begin{array}{l}\text { Incentivar a ter contato com outras crianças (levar na casa dos amigos, receber } \\
\text { os amigos em casa etc.) }\end{array}$ & 4,52 & 1,36 \\
\hline
\end{tabular}

Nota: Não houve diferenças significativas entre os grupos de participantes. A pontuação varia entre 1 (nunca) e 6 (uma vez por dia). Fonte: As autoras.

Tabela 4 - Relação entre as condiçōes de trabalho das mães que trabalhavam fora e 0 envolvimento com os filhos

\begin{tabular}{|c|c|c|c|c|c|c|}
\hline \multirow[t]{2}{*}{ Tipo de envolvimento } & \multicolumn{2}{|c|}{$\begin{array}{c}\text { Satisfação com o } \\
\text { trabalho }\end{array}$} & \multicolumn{2}{|c|}{$\begin{array}{c}\text { Ambiente interpessoal } \\
\text { de trabalho }\end{array}$} & \multicolumn{2}{|c|}{ Carga de trabalho } \\
\hline & $p$ & $\mathbf{n}$ & $p$ & $\mathbf{n}$ & $p$ & $\mathbf{n}$ \\
\hline Participação da mãe nos cuidados com os filhos & 0,47 & 9 & & 8 & & 11 \\
\hline Participação do pai nos cuidados com os filhos & & 8 & & 7 & 0,36 & 10 \\
\hline Tempo que a mãe passa com os filhos & & 17 & $-0,32$ & 15 & $-0,51+$ & 19 \\
\hline Comunicação com os filhos & $0,51+$ & 15 & $0,72^{* *}$ & 13 & & 19 \\
\hline Interação entre mãe e filhos & 0,34 & 14 & $-0,30$ & 12 & $-0,42$ & 16 \\
\hline $\begin{array}{l}\text { Participação da mãe nas atividades escolares, } \\
\text { culturais e de lazer dos filhos }\end{array}$ & $0,69^{*}$ & 12 & & 10 & $-0,36$ & 15 \\
\hline
\end{tabular}

\begin{tabular}{cl}
\hline Legenda: + & $p<0,1$ \\
$*$ & $p<0,05$ \\
$* *$ & $p<0,01$
\end{tabular}

Fonte: As autoras. 
possibilidade é que algumas das mães desenvolviam relacionamentos tão fortes no ambiente de trabalho, que acabavam não buscando aprofundar os relacionamentos com os familiares.

Outro aspecto a ser destacado é a correlação negativa entre a carga de trabalho e o tempo que se passa com os filhos, o que indica que quanto maior a carga de trabalho, menor o tempo disponível para estar com o filho. Esse ponto reforça a já tão difundida ideia de que o tempo de trabalho é inversamente proporcional à disponibilidade para estar com os filhos.

Assim, as correlações encontradas mostram que níveis maiores de satisfação no trabalho tiveram um impacto positivo nas interações com os filhos, mas a carga e o ambiente interpessoal de trabalho (mesmo que um ambiente positivo) das mães estavam tendo um impacto negativo nas interações com os filhos. Este resultado reflete as vantagens (financeiras e bem-estar da mãe) e desvantagens (falta de tempo) apontadas pelas mães em relação a seu trabalho fora de casa.

\section{Conclusões}

A satisfação com o emprego e a qualidade do ambiente interpessoal de trabalho levam à melhora da saúde física e mental da mulher, o que a deixa mais disposta para participar na educação dos filhos, sem a necessidade de conversar com eles a todo o momento e mais segura para solicitar a participação de seu cônjuge nas rotinas domésticas, sendo que quanto mais este participa, mais tempo a mãe tem para interagir com as crianças e envolver-se com outros interesses pessoais. Nesse sentido, percebe-se a importância da qualidade do ambiente de trabalho enquanto mediador para o estabelecimento de relações familiares positivas e para o desenvolvimento socioemocional e escolar dos filhos. Assim, este estudo aponta para a existência de uma relação muito importante entre as condições de trabalho e a vida familiar e para as vantagens e desvantagens de se exercer uma atividade remunerada fora do lar.

\section{Pesquisas Futuras}

Seria interessante investigar uma variedade maior de demandas ou condições de trabalho que podem afetar a disponibilidade de tempo e o bem-estar psicológico da mãe para participar das rotinas familiares, em especial, das atividades de seus filhos. Por exemplo, mulheres com cargos mais elevados podem ter uma carga horária maior e responsabilidades que requerem mais envolvimento psicológico, o que pode reduzir o tempo familiar disponível, interferindo na relação com os filhos. Além disso, mesmo em funções semelhantes às exercidas pelas mulheres dessa amostra, o tempo de locomoção até o local de trabalho em grandes cidades pode aumentar significativamente a jornada de trabalho total, com o mesmo resultado.

\section{Referências}

Antunes, C. (2003) Jogos para estimulação das múltiplas inteligências. (12a ed.). Petrópolis: Vozes.

Bertolini, L. B. A. (2002) Relações entre o trabalho da muIher e a dinâmica familiar. (2a ed.). São Paulo: Vetor.

Bruschini, M. C. A. (2007) Trabalho e gênero no Brasil nos últimos dez anos. Cadernos de Pesquisa, 37(132), 537-572.

Bruschini, C. (2006) Trabalho domestico: inatividade econômica ou trabalho não renumerado? Revista brasileira de estudos de população, 23(2), 331-353.

Bruschini, C., \& Lombardi, M. R. (1999) A bipolaridade do trabalho feminino no Brasil: o emprego doméstico e as "novas" ocupações. GT trabalho e sociedade: XXIII Reunião anual da Ampocs, Caxambu, MG, Brasil.

Cooper, G. \& Lewis, S. (2000) E agora, trabalho ou família? Pais e mães que trabalham fora aprendem como enfrentar as sobrecargas profissionais e familiares do dia a dia. (N. Montigelli Junior Trad.). (1a ed.). São Paulo: Tamisa.

Cortazzo, I. E Moise, C. (2000) Estado, salud y desocupacion, de La vulnerabilida a La exclusion. Buenos Aires: Paidos.

D’Affonseca, S. M. (2005). Importância do envolvimento materno para o autoconceito e desempenho acadêmico das crianças de baixo nível socioeconômico. Dissertação de mestrado apresentado ao Programa de Educação Especial, Universidade Federal de São Carlos, SP.

Psicol. Argum. 2014 jan./mar., 32(76), 129-138 
Diniz, G. (1999) Homens e mulheres frente à interação casamento trabalho: aspectos da realidade brasileira. In T. F. Carneiro (Org.), Casal e família: entre a tradição e a transformação (pp. 31-54). Rio de Janeiro: Nau.

Gottman, J., \& Declaire, J. (2001) Inteligência emocional e a arte de educar nossos filhos: como aplicar os conceitos revolucionários de inteligência emocional para uma compreensão da relação entre pais e filhos. (A. C. da Silva Trad.). Rio de Janeiro: Objetiva.

Gottlieb, B. H., Kelloway, E. K., \& Barham, E. (1998). Flexible work arrangements managing the workfamily boundary. Chichester: John Wiley.

Gravena. A. C. (2006). Retorno ao trabalho após o nascimento de um filho: percepções de professoras sobre sua experiência. Dissertação de Mestrado. Universidade Federal de São Carlos: São Carlos.

Grollman, E. A., \& Sweder, G.L. (1991) Pais que trabalham fora: como conciliar com sucesso filhos com carreira. (M. S. M. Neto Trad.). (3a ed.). São Paulo: Saraiva

Hartmann, J. B., Almeida, E. G., Ribeiro, A. B., Marcelino, D. B., Martins, E. J., Zanella, L. S., Fachina, J. L., \& Gava, T. (2001, abril). A relação materna e familiar com o desenvolvimento de um quadro de megacólon congênito. II Congresso iberoamericano de psicologia clínica e da saúde, Guarujá, SP, Brasil. p. 330.
Maldonado, M. T. (1985) Comunicação entre pais e filhos: a linguagem do sentir. Petrópolis: Vozes.

Maluf, M., \& Mott, M. L. (1998). Recônditos do mundo feminino. In F. A. Novais \& N. Sevcenko (Orgs.). História da vida privada no Brasil. (Vol. 3). São Paulo: Companhia das Letras.

McGoldrick, M. (1995) As mulheres e o ciclo de vida familiar. In B. Carter \& M. McGoldrick (Orgs.). As mudanças no ciclo de vida familiar: uma estrutura para a terapia familiar. (M. A. V. Veronese Trad., pp. 30-64). Porto Alegre: Artes Médicas.

Probst, E.R. \& Ramos, P. A. (2003) evolução da mulher no mercado de trabalho. Revista Leonardo Pós. (Instituto Catarinense de pós-graduação). 1(2), p.35-38.

Sayão, R. (2003) Como educar meu filho? Princípios e desafios da educação de crianças e de adolescentes hoje. São Paulo: Publifolha. 